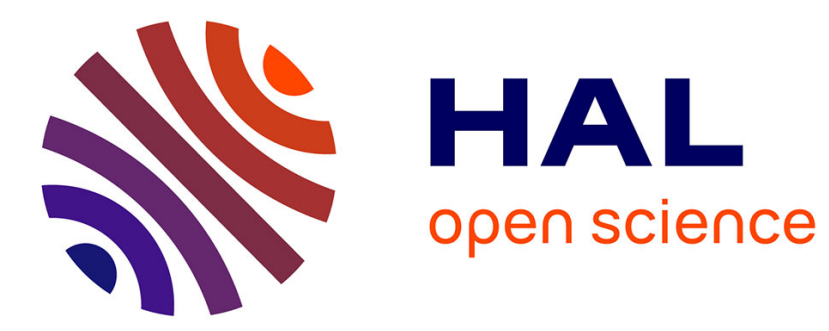

\title{
Tough Polymeric Hydrogels Formed by Natural Glycyrrhetinic Acid-Tailored Host-Guest Macro-Cross-Linking toward Biocompatible Materials
}

Ge Xu, Jiawei Li, Jianqiao Wu, Hao Zhang, Jun Hu, Min-Hui Li

\section{- To cite this version:}

Ge Xu, Jiawei Li, Jianqiao Wu, Hao Zhang, Jun Hu, et al.. Tough Polymeric Hydrogels Formed by Natural Glycyrrhetinic Acid-Tailored Host-Guest Macro-Cross-Linking toward Biocompatible Materials. ACS Applied Polymer Materials, 2019, 1 (10), pp.2577-2581. 10.1021/acsapm.9b00723 . hal-03051825

\section{HAL Id: hal-03051825 \\ https://hal.science/hal-03051825}

Submitted on 22 Dec 2020

HAL is a multi-disciplinary open access archive for the deposit and dissemination of scientific research documents, whether they are published or not. The documents may come from teaching and research institutions in France or abroad, or from public or private research centers.
L'archive ouverte pluridisciplinaire HAL, est destinée au dépôt et à la diffusion de documents scientifiques de niveau recherche, publiés ou non, émanant des établissements d'enseignement et de recherche français ou étrangers, des laboratoires publics ou privés. 


\title{
Tough Polymeric Hydrogels Formed by Natural Glycyrrhetinic Acid- Tailored Host-Guest Macro-Crosslinking Toward Biocompatible Ma- terials
}

\author{
$\mathrm{Ge} \mathrm{Xu},{ }^{\dagger}$ Jiawei $\mathrm{Li},{ }^{\dagger}$ Jianqiao $\mathrm{Wu},{ }^{\dagger}$ Hao Zhang, ${ }^{\dagger}$ Jun $\mathrm{Hu}^{*, \dagger}$ and Min-Hui $\mathrm{Li}^{*,+, \uparrow}$ \\ ${ }^{\dagger}$ Beijing Advanced Innovation Center for Soft Matter Science and Engineering, Beijing University of Chemical Tech- \\ nology, Beijing 100029, China \\ ${ }^{\ddagger}$ Chimie ParisTech, PSL University Paris, CNRS, Institut de Recherche de Chimie, Paris 75005, France \\ KEYWORDS: polymeric hydrogel, host-guest pairs, cyclodextrins, glycyrrhetinic acid, natural product
}

\begin{abstract}
Host-guest polymeric hydrogels often suffer from poor biocompatibility and weak mechanical strength owing to the low complexation degree between host- and guest-polymers. In contract to reported works, here a biocompatible host-guest macro-crosslinker (HGMC) was synthesized beforehand by complexation of poly( $\beta$-cyclodextrin) with natural glycyrrhetinic acid-derivative functionalized with acrylates at two extremities. After crosslinking polyacrylamide three polymeric hydrogels were obtained, the swelling ratios and micro-pore sizes of which could be adjusted effectively by HGMC content. Moreover, they exhibited robust anti-compressing and elastic features. These biocompatible tough polymeric hydrogels hold the promise for potential applications as biomaterials.
\end{abstract}

Host-guest polymeric hydrogels, consisting of 3 D networks crosslinked by host-guest interactions, have attracted considerable attention by virtue of their distinct stimuli responsiveness and inherent processability. ${ }^{[-3]}$ Currently, one of the most common strategies is to prepare host-polymers and guest-polymers by grafting host and guest functional groups on polymer main chains, respectively. ${ }^{[4-6]} \mathrm{Un}$ fortunately, low grafting degrees are often obtained because of the steric hindrance of polymer backbones, thus leading to the weak mechanical strength. In addition, these hydrogels also suffer from poor biocompatibility as nonrenewable host-guest pairs are frequently used, which further restricts their applications in biocompatible materials. ${ }^{[7-9]}$ Thus, it is of great importance to develop a simple yet useful method for constructing host-guest polymeric hydrogels with high mechanical strength from biocompatible host-guest pairs.

Cyclodextrins (CDs), cyclic oligomers of $D-(+)$-glucose linked via $\alpha-1,4$-glucose bond, are produced from enzymatic processing of starch with good biocompatibility and availability. ${ }^{[1]]}$ More importantly, the hydrophobic cavity of CDs makes them typical host molecules to bind with various guest molecules like adamantane, ${ }^{[1,1,1]}$ azobenzene, ${ }^{[13,14]}$ ferrocene, ${ }^{[15,16]}$ cholic acid, ${ }^{[17,18]}$ and glycyrrhetinic acid, ${ }^{[19,20]}$ according to the size and hydrophobicity. As firstly reported by us in 2016, natural glycyrrhetinic acid (GA) has a mild binding affinity with $\beta$-cyclodextrin $(\beta$-CD) $\left(K_{\mathrm{a}}=1.59 \times 10^{3} \mathrm{M}^{-1}\right)$ and great biocompatibility. ${ }^{[19]} \mathrm{GA}$ is a 30 $\mathrm{C}$-containing plant metabolite in licorice root and possesses a variety of remarkable biocompatibility and biological activities. ${ }^{[2]}$ The fused pentacyclic structure offers GA a rigid molecular backbone of nanometric dimensions. Besides, the presence of hydroxyl and carboxyl groups with several chiral centers makes GA an interesting building block for chiral assemblies and materials. ${ }^{[22-24]}$ In our previous works, we found that the GA/ $\beta$-CD pair adjusted the LCST (lower critical solution temperature) behavior of copolymers composed of GA-based methacrylate and $N, N^{\prime}$ dimethylacrylamides, ${ }^{[25]}$ dictated the construction of polypseudorotaxanes of GA-tailored polyurethane, ${ }^{[20]}$ and drove the formation of self-healable supramolecular hydrogels by grafting GA and $\beta$-CD to $N, N^{\prime}$-dimethylacrylamide copolymers. ${ }^{[19]}$ Obviously, GA/ $\beta$-CD is an ideal biocompatible host-guest pair for constructing the host-guest polymeric hydrogels.

In order to circumvent the weak mechanical strength of $\mathrm{GA} / \beta$-CD hydrogels caused by the low grafting degree of GA and $\beta$-CD on polymer backbones, in this research we reported a simple strategy for preparing tough host-guest polymeric hydrogels by using a macro-crosslinker. In this strategy, the GA-derivative with two terminal acrylates (GADA) and poly $(\beta$-cyclodextrin) (PCD) were used as biocompatible guest and host to fabricate the host-guest macro-crosslinker (HGMC) beforehand. After that, the rotaxane-type hydrogels were produced by crosslinking acrylamide (AAm) in the presence of HGMC via a UV photo-polymerization (Scheme 1). There were several advantages in this strategy: 1) the host-guest complexation was formed before the polymerization, which avoided the issues of steric hindrance of polymer backbones; 2 ) besides the crosslinking between GADA and polyacrylamide, the inclusion between PCD and GADA provided additional crosslinking sites, which endowed the hydrogels better 
mechanical performance; 3) when external forces were applied to the hydrogels, the host-guest interactions between PCD and GADA in these rotaxane-type hydrogels could dissipate energy by sliding $\beta$-CD from GA backbone, consequently making the hydrogels very tough. The results showed that all the hydrogels with different molar ratios of HGMC and AAm were anti-compressing, nonfragile and elastic. Moreover, they could easily recover to their original states on account of the host-guest interactions. This work provided an effective way to construct biocompatible polymeric hydrogels with good mechanical strength for potential applications as biomaterials in soft-tissue repair.

Scheme 1. Schematic illustration of (A) glycyrrhetinic acid-derivative functionalized with acrylates at two extremities (GADA), (B) poly( $\beta$-cyclodextrin) (PCD), and $(\mathrm{C})$ polymeric hydrogels formed by host-guest macro-crosslinking.

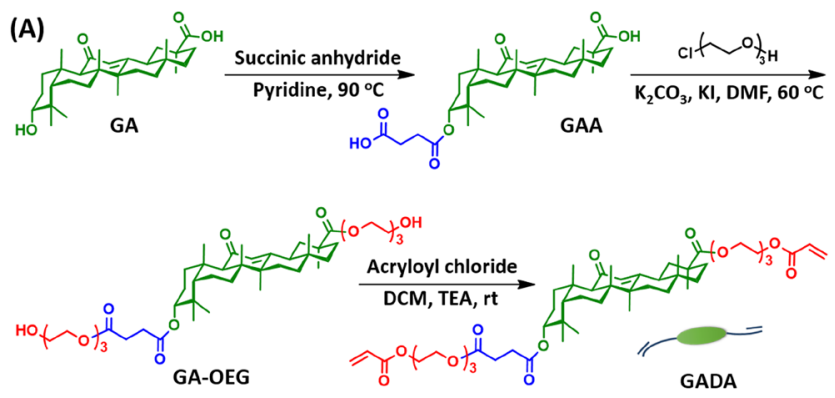

(B)
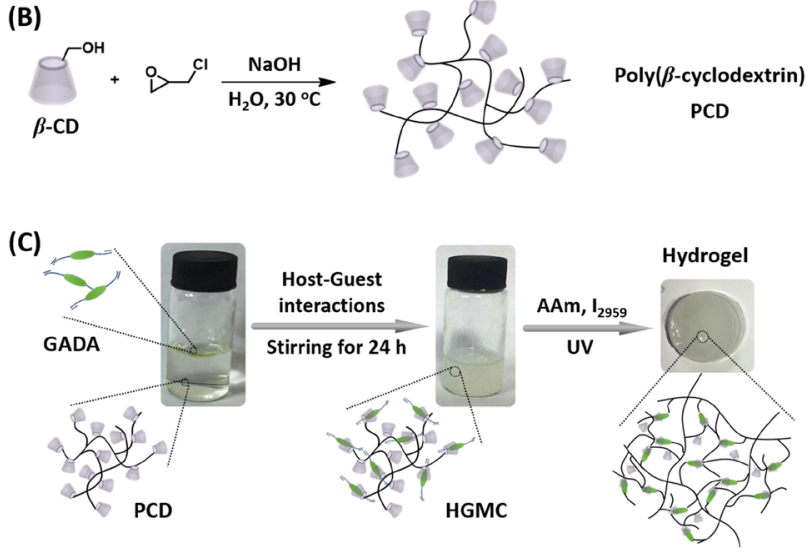

For the preparation of host-guest macro-crosslinker HGMC, GADA and PCD were firstly synthesized as shown in Scheme $1 A$ and $1 B$. GA reacted with succinic anhydride to give the intermediate (GAA) with proton signals at 2.65 and $2.69 \mathrm{ppm}$ assigning to methylene groups $\left(\mathrm{H}_{\mathrm{a}}, \mathrm{H}_{\mathrm{b}}\right.$, Figure $1 \mathrm{~A})$. 2-[2-(2-chloroethoxy)ethoxy]ethanol was then conjugated to GAA via an ester reaction, affording another intermediate (GA-OEG) with peaks at 3.60 3.73 and 4.18 4.37 ppm belonging to methylene groups of OEG moiety $\left(\mathrm{H}_{\mathrm{c}}, \mathrm{H}_{\mathrm{d}}, \mathrm{H}_{\mathrm{e}}\right.$, Figure $\left.{ }_{1 B}\right)$. Lastly, the guest molecule GADA was obtained by reacting GA-OEG with acryloyl chloride, and the classic proton signals from terminal acrylates at 5.85, 6.15 and 6.40 ppm $\left(\mathrm{H}_{\mathrm{g}}, \mathrm{H}_{\mathrm{h}}, \mathrm{H}_{\mathrm{i}}\right)$ were observed clearly (Figure $1 \mathrm{C}$ ), strongly indicating the successful synthesis of GADA. On the other hand, PCD was synthesized through copolymerizing epichlorohydrin with $\beta$-CD. As can be seen from ${ }^{13} \mathrm{C}$ NMR spectrum (Figure $\mathrm{S}_{1}$ ), the peaks at 62 and $72 \mathrm{ppm}$ were assigned to the characteristic methylene carbon formed in the polycondensation of epichlorohydrin with $\beta$-CD. ${ }^{[26,27]}$ Besides, the size exclusion chromatography (SEC) showed that PCD had a molecular weight $\left(M_{\mathrm{n}}\right) 7300 \mathrm{Da}$ (calibrated with polystyrene standard, Figure 2A).

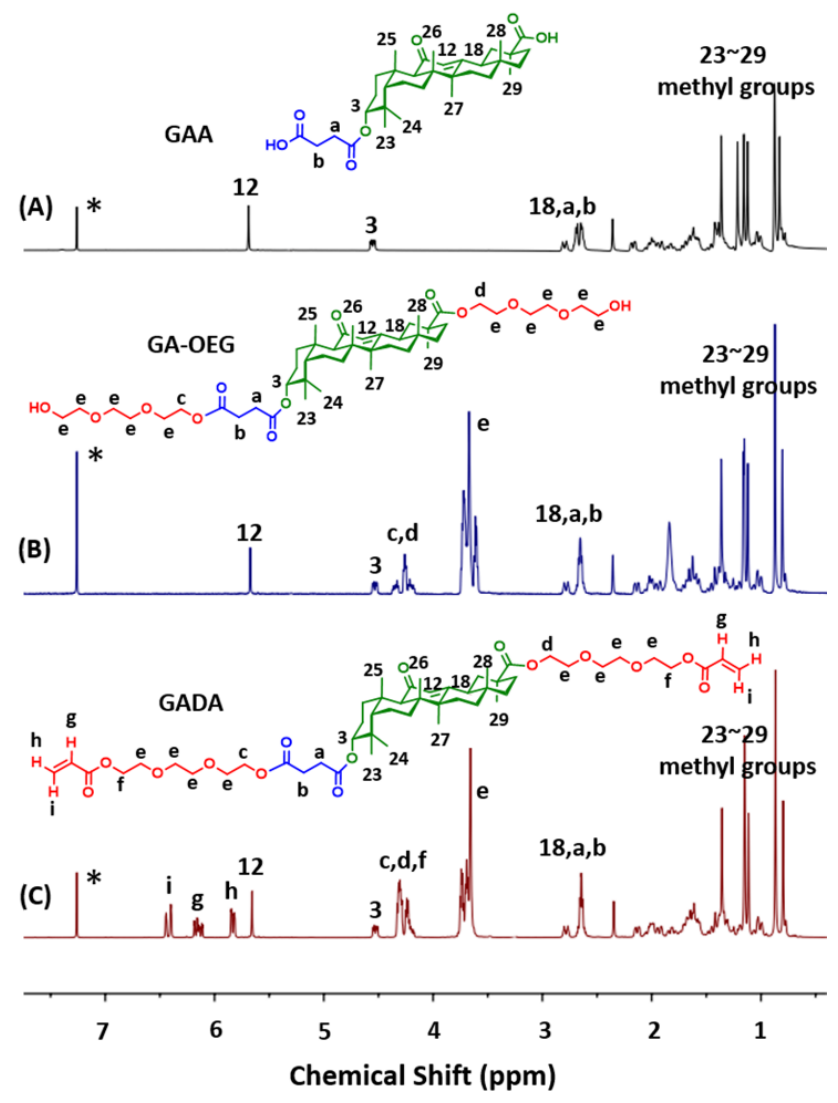

Figure 1. ${ }^{1} \mathrm{H}$ NMR spectra of (A) GAA, (B) GA-OEG and (C) GADA (40o $\mathrm{MHz}, \mathrm{CDCl}_{3}$ ). *represents the solvent peak.

Subsequently, the macro-crosslinker HGMC was prepared by mixing the oil-like GADA into an aqueous solution of PCD. As shown in Scheme ${ }_{1} \mathrm{C}$, after stirring for $24 \mathrm{~h}$, the light yellow oil of GADA floating on the up-layer of PCD aqueous solution disappeared and a homogeneous dispersed solution was generated, because the hydrophobic interior cavity of PCD had trapped GADA. To clarify the host-guest interactions between GADA and PCD, ${ }^{1} \mathrm{H}$ NMR, SEC and X-ray diffraction (XRD) measurements were performed. No signal of methyl groups on GA moiety was observable in ${ }^{1} \mathrm{H}$ NMR spectrum of GADA in $\mathrm{D}_{2} \mathrm{O}$ (Figure $2 \mathrm{~B}$, up), which indicated the formation of aggregates due to the hydrophobic nature of GA. Upon addition of PCD signals for methyl protons (positions 23-29) appeared on account of the complexation of GA with PCD (Figure $2 \mathrm{~B}$, bottom $)^{[1,20,25]}$. It was consistent with the SEC results, where a larger molecular weight $\left(M_{\mathrm{n}}\right) 9400$ Da of HGMC was detected in comparison with that of PCD (Figure 2A). According to Formula $S_{1}$ in Supporting Information, the molar ratio between $\beta$-CD and GADA was calculated to be 2:1. More evidence came from XRD diffraction patterns. As shown in Figure $\mathrm{S}_{2}$, a certain crystalline structures of PCD were demonstrated by two peaks at $2 \theta=12.7$ and $18.8^{\circ}$ in 
the diffractogram, corresponding to repeating distances of 0.70 and $0.47 \mathrm{~nm}$. Conversely, there was only a broad scattering signal in the range of $6-50^{\circ}$ for HGMC, because the complexation of PCD with GADA prevented the crystallization of PCD. ${ }^{[28]}$
(A)

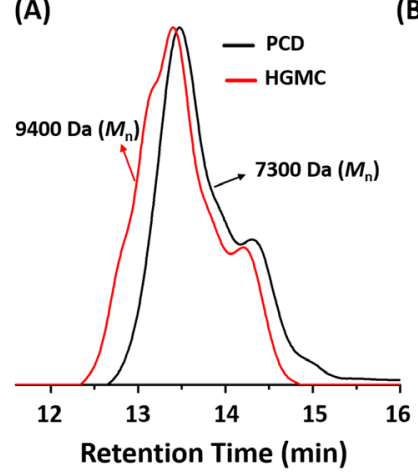

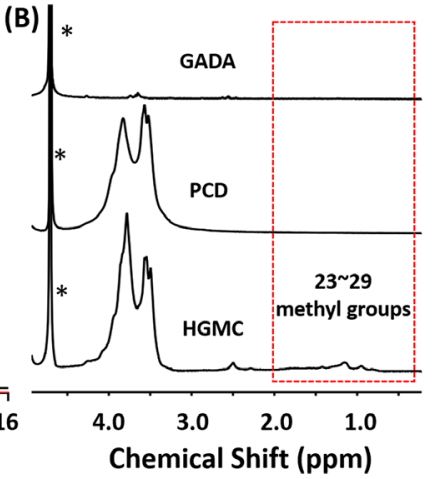

Figure 2. (A) SEC spectra of PCD and HGMC with refractometer as detector (DMF as eluent, polystyrene standards for molecular weights calibration). (B) ' $\mathrm{H}$ NMR spectra of GADA (up), PCD (middle) and HGMC (bottom) in $\mathrm{D}_{2} \mathrm{O}$ (40o MHz). *represents the solvent peak.

Table 1. Formulations and swelling properties of Gel1, Gel-2 and Gel-3.

\begin{tabular}{lccccc}
\hline Gels & $\begin{array}{c}\text { HGMC } \\
(\mathbf{m m o l})\end{array}$ & $\begin{array}{c}\text { AAm } \\
(\mathbf{m m o l})\end{array}$ & $\begin{array}{c}\text { Molar } \\
\text { Ratio }^{\mathrm{a}}\end{array}$ & $\begin{array}{c}\text { Water } \\
\text { Content }\end{array}$ & $\begin{array}{c}\text { Swelling } \\
\text { Ratio }^{\mathbf{b}}\end{array}$ \\
\hline Gel-1 & 0.12 & 12 & 0.010 & $52 \%$ & $487 \%$ \\
\hline Gel-2 & 0.18 & 12 & 0.015 & $46 \%$ & $339 \%$ \\
\hline Gel-3 & 0.24 & 12 & 0.020 & $41 \%$ & $249 \%$ \\
\hline a[HGMC]/[AAm]; b Gels were swollen in DI-water for $24 \mathrm{~h}$. \\
\hline
\end{tabular}

Having macro-crosslinker HGMC in hands, the hydrogels were prepared by polymerizing AAm with the presence of HGMC and photo-initiator $\mathrm{I}_{2959}$ via a UV photopolymerization (Scheme $1 \mathrm{C}$ ). As illustrated in Table 1, three hydrogels, Gel-1, Gel-2 and Gel-3, were successfully prepared with different contents of HGMC. The swelling results showed that Gel-1, Gel-2 and Gel-3 in deionized (DI) water swelled more than $100 \%$ in the first $1 \mathrm{~h}$, and then the volume continued to increase steadily. After $24 \mathrm{~h}$, the equilibrium state was achieved with an order of swelling ratio Gel-1 > Gel-2 > Gel-3 (Figure 3A, Table 1). The reason was that as the concentration of HGMC increased, the crosslinking density was enhanced while the flexibility of networks was decreased, thus leading to a reduction in the swelling ratio. Moreover, scanning electron microscopy (SEM) images were used to reveal their microstructures. Before subjecting to SEM analysis, hydrogels at swelling equilibrium were lyophilized under vacuum at $-60^{\circ} \mathrm{C}$ and then coated by gold. As shown in Figure ${ }_{3} \mathrm{~B}-\mathrm{D}$, the microporous structures of Gel-1, Gel-2 and Gel-3 were observed, and the pore sizes tended to be smaller from Gel-1 to Gel3, which was consistent with the swelling results. Apparently, the hydrogels had the $3 \mathrm{D}$ crosslinked networks with micro-pore structures, and their swelling behaviors and pore sizes could be adjusted effectively by the content of macro-crosslinker HGMC.

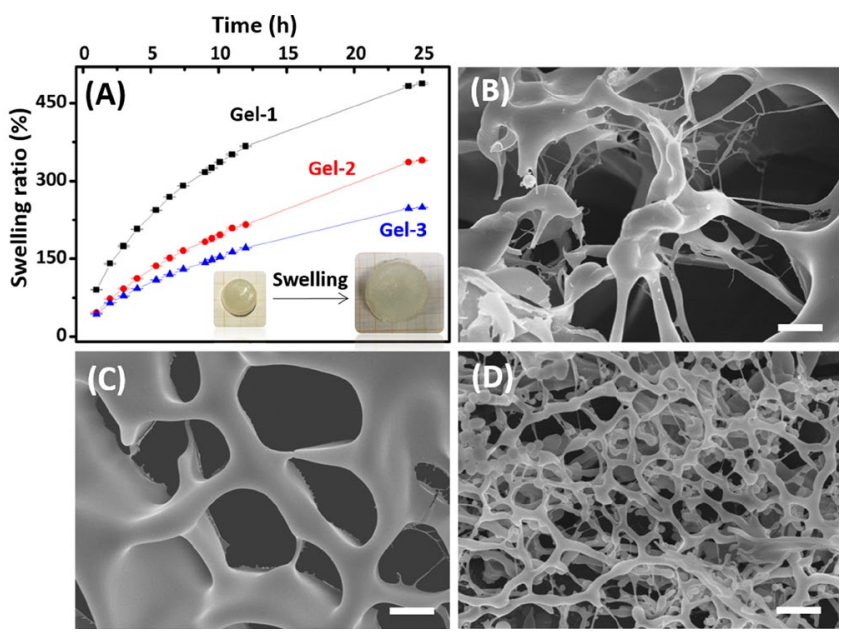

Figure 3. (A) Swelling behaviors and (B, C, D) SEM images of Gel-1, Gel-2 and Gel-3. Scale bar is $2 \mu \mathrm{m}$ for (B), (C) and (D).

Oscillatory rheology technique was used to measure the mechanical properties of Gel-1, Gel-2 and Gel-3. The frequency sweep results showed that all the hydrogels exhibited a higher storage modulus $\left(G^{\prime}\right.$, in the order of $10^{4}$ Pa) compared to the loss modulus $\left(G^{\prime \prime}\right.$, in the order of $10^{3}$ $\mathrm{Pa})$ in the range from 1 to $100 \mathrm{~Hz}$, revealing their viscoelastic behaviors (Figure $4 \mathrm{~A}$ ). Moreover, with the increase in concentration of HGMC, the $G^{\prime}$ value was increased significantly, that is, 9770 Pa for Gel-1, $11830 \mathrm{~Pa}$ for Gel-2, and 1499o Pa for Gel-3 (at frequency $=10 \mathrm{~Hz}$ ), which was mainly attributed to the enhanced crosslinking density of hydrogel networks. The strain amplitude sweeps were also employed to determine the deformation limit. As shown in Figure $4 \mathrm{~B}$, the transition of $G^{\prime}$ and $G^{\prime \prime}$ occurred at the strain of $130 \%, 540 \%$, and $1200 \%$ for Gel-1, Gel-2 and Gel-3 under a frequency of $1 \mathrm{~Hz}$, which implied the beginning of destruction of hydrogel networks at such a strain. ${ }^{[29]}$
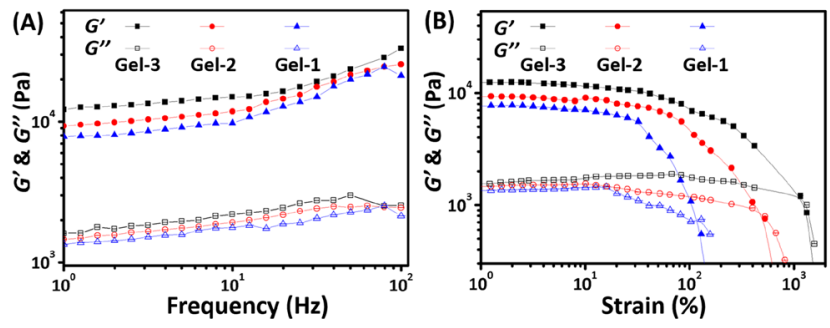

Figure 4. (A) Oscillatory frequency sweep of Gel-1, Gel-2 and Gel-3 at a strain 1\%; (B) G' and G' of Gel-1, Gel-2 and Gel-3 as a function of strain at a frequency of $1 \mathrm{~Hz}$.

Furthermore, the compression, cyclic compression and tensile tests of all the hydrogels were performed to investigate their mechanical properties. As shown in Figure $5 \mathrm{~A}$, all of them had the good mechanical strength, and no yield or breaking point was observed for each hydrogel during the compression process until pressure of $0.81,1.20$ and $1.63 \mathrm{kPa}$ for Gel-1, Gel-2 and Gel-3, respectively. This observation clearly revealed their nonfragile nature. More- 
over, as the concentration of macro-crosslinker HGMC increasing, the crosslinking density of networks was enhanced, thus resulting in an increase in the modulus from 1.28 to $1.71 \mathrm{kPa}$ (Figure ${ }_{5} \mathrm{~B}$ ). In addition, after three loadingunloading compression tests, the hydrogel was still intact keeping the original state and nearly identical strength at maximum deformation, although there was a hysteresis (Figure ${ }_{5} \mathrm{C}$ ). It should be noted that this hysteresis was normal in the hydrogel systems with the presence of hostguest interactions, which meant that the compression energy was dissipated effectively by sliding $\beta$-CD from GA backbone in hydrogels. ${ }^{\left[{ }^{\circ}\right]}$ Besides, the maximal stretching strain of Gel-1, Gel-2 and Gel-3 reached 454\%, 297\%, and $131 \%$, respectively, with fairly elasticity in the stretched stats (Figure ${ }_{5} \mathrm{D}$ ). All the above results indicated that our hydrogels were anti-compressing, nonfragile and elastic, and could recover to their original states on account of the non-covalent host-guest interactions.
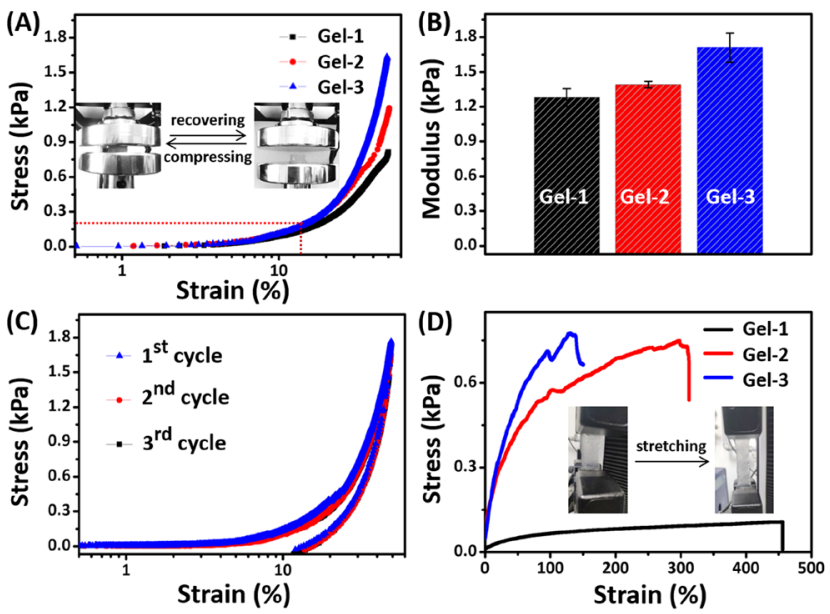

Figure 5. (A) Mechanical compression curves of Gel-1, Gel-2 and $\mathrm{Gel}-3$, and (B) their responding compression modulus. (C) Cyclic compression curves of Gel-3. (D) Mechanical tensile curves of Gel-1, Gel-2 and Gel-3.

In summary, to address the issue of low mechanical strength of previously reported polymeric hydrogels made of host-group-grafted polymers and guest-group-grafted polymers, a biocompatible host-guest macro-crosslinker HGMC was synthesized by complexation of natural GAderivative with terminal acrylates (GADA) with poly $(\beta$-cyclodextrin) (PCD), which was confirmed by NMR, SEC and XRD studies. Three polymeric hydrogels were prepared via a UV photo-polymerization of AAm with different contents of HGMC. The swelling tests and SEM images revealed that all the hydrogels had ${ }_{3} \mathrm{D}$ crosslinked structures with micro-pores, and their swelling ratios and pore sizes could be adjusted effectively by the content of HGMC. In addition, they exhibited the great anti-compressing, nonfragile and elastic features, which were mainly attributed to the host-guest macro-crosslinker HGMC. This work provided an effective way to prepare biocompatible tough polymeric hydrogels, which might be applied as biomaterials in soft-tissue repair.

\section{ASSOCIATED CONTENT}

Supporting Information. Materials and methods; synthesis of GADA and its intermediates; synthesis of PCD; fabrication of HGMC inclusion complex and preparation of hydrogels with different contents of HGMC; ${ }^{13}$ C NMR spectrum of PCD in $\mathrm{D}_{2} \mathrm{O}$; X-ray diffraction patterns of PCD, GADA and HGMC; ${ }^{1} \mathrm{H}-,{ }^{13} \mathrm{C}-\mathrm{NMR}$ and MS spectra of GAA, GA-OEG and GADA, respectively.

\section{AUTHOR INFORMATION}

\section{Corresponding Author}

*E-mail: jhu@mail.buct.edu.cn

*E-mail: min-hui.li@chimieparistech.psl.eu

Notes

The authors declare no competing financial interest.

\section{ACKNOWLEDGMENT}

This work is supported by NSFC (no. 21604085, 21604001) and National Key R\&D Program of China (no. 2017YFDo200302).

\section{REFERENCES}

1. Ma, C.; Li, T.; Zhao, Q.; Yang, X.; Wu, J.; Luo, Y.; Xie, T. Supramolecular lego assembly towards three-dimensional multi-responsive hydrogels. Adv. Mater. 2014, 26, 5665-5669.

2. Loh, X. Supramolecular host-guest polymeric materials for biomedical applications. Mater. Horiz. 2014, 1, 185-195.

3. Dong, R.; Pang, Y.; Su, Y.; Zhu, X. Supramolecular hydrogels: synthesis, properties and their biomedical applications. Biomater. Sci. 2015, 3, 937-954.

4. Jia, Y.; Zhang, M.; Zhu, X. CO2-switchable self-healing hostguest hydrogels. Macromolecules 2o17, 50, 9696-9701.

5. Jin, J.; Cai, L.; Jia, Y.; Liu, S.; Chen, Y.; Li, R. Progress in selfhealing hydrogels assembled by host-guest interactions: preparation and biomedical applications. J. Mater. Chem. B. 2019, 7, 16371651 .

6. Deng, Z.; Guo, Y.; Zhao, X.; Ma, P.; Guo, B. Multifunctional stimuli-responsive hydrogels with self-healing, high conductivity, and rapid recovery through host-guest interactions. Chem. Mater. 2018, 30, 1729-1742.

7. Ma, X.; Zhou, N.; Zhang, T.; Hu, W.; Gu, N. Self-healing pHsensitive poly[(methyl vinyl ether)-alt-(maleic acid)]-based supramolecular hydrogels formed by inclusion complexation between cyclodextrin and adamantane. Mater. Sci. Eng., C. 2017, 73, 357-365.

8. Cai, T.; Huo, S.; Wang, T.; Sun, W.; Tong, Z. Self-healable tough supramolecular hydrogels crosslinked by polycyclodextrin through host-guest interaction. Carbohydr. Polym. 2018, 193, 5461.

9. Appel, E. A.; Biedermann, F.; Rauwald, U.; Jones, S. T. Supramolecular cross-linked networks via host-guest complexation with cucurbit[8] uril. J. Am. Chem. Soc. 2010, 132, 14251-1426o.

10. Harada, A.; Takashima, Y.; Nakahata, M. Supramolecular polymeric materials via cyclodextrin-guest interactions. Acc. Chem. Res. 2014, 47, 2128-2140.

11. Rodell, C. B.; Kaminski, A. L.; Burdick, J. A. Rational design of network properties in guest-host assembled and shear-thinning hyaluronic acid hydrogels. Biomacromolecules 2013, 14, 4125-4134.

12. Guo, X.; Wang, J.; Li, L.; Pham, D.; Clements, P.; Lincoln, S. F.; May, B. L.; Chen, Q.; Zheng, L.; Prudhomme, R. K. Tailoring polymeric hydrogels through cyclodextrin host-guest complexation. Macromol. Rapid Commun. 2010, 31, 300-304.

13. Wang, M.; Zhang, X.; Li, L.; Wang, J.; Wang, J.; Ma, J.; Yuan, Z.; Lincoln, S. F.; Guo, X. Photo-reversible supramolecular hydrogels assembled by $\alpha$-cyclodextrin and azobenzene substituted poly(acrylic acid)s: effect of substitution degree, concentration, 
and tethered chain length. Macromol. Mater. Eng. 2016, 301, 191198.

14. Tamesue, S.; Takashima, Y.; Yamaguchi, H.; Shinkai, S.; Harada, A. Photoswitchable supramolecular hydrogels formed by cyclodextrins and azobenzene polymers. Angew. Chem. Int. Ed. 2010, 49, 7461-7464.

15. Du, P.; Liu, J.; Chen, G.; Jiang, M. Dual responsive supramolecular hydrogel with electrochemical activity. Langmuir 2011, 27, 9602-9608.

16. Tan, L.; Liu, Y.; Ha, W.; Ding, L.; Peng, S.; Zhang, S.; Li, B. Stimuli-induced gel-sol transition of multi-sensitive supramolecular $\beta$-cyclodextrin grafted alginate/ferrocene modified pluronic hydrogel. Soft Matter 2012, 8, 5746-5749.

17. Jia, Y.; Jin, J.; Liu, S.; Ren, L.; Luo, J.; Zhu, X. Self-healing hydrogels of low molecular weight poly(vinyl alcohol) assembled by host-guest recognition. Biomacromolecules 2018, 19, 626-632.

18. Jia, Y.; Zhu, X. Self-healing supramolecular hydrogel made of polymers bearing cholic acid and $\beta$-cyclodextrin pendants. Chem. Mater. 2015, 27, 387-393.

19. Li, Y.; Li, J.; Zhao, X.; Yan, Q.; Gao, Y.; Hao, J.; Hu, J.; Ju, Y. Triterpenoid-based self-healing supramolecular polymer hydrogels formed by host-guest interactions. Chem. Eur. J. 2016, 22, 18435-18441.

20. Hao, J.; Gao, Y.; Zheng, C.; Liu, J.; Hu, J.; Ju, Y. Natural-product-tailored polyurethane: size-dictated construction of polypseudorotaxanes with cyclodextrin-triterpenoid pairs. ACS Macro. Lett. 2018, 7, 1131-1137.

21. Zhang, C.; Wang, W.; Liu, T.; Wu, Y.; Guo, H.; Wang, P.; Tian, Q.; Wang, Y.; Yuan, Z. Doxorubicin-loaded glycyrrhetinic acidmodified alginate nanoparticles for liver tumor chemotherapy. $\mathrm{Bi}$ omaterials 2012, 33, 2187-2196.

22. Wan, Z.; Sun, Y.; Ma, L.; Zhou, F.; Guo, J.; Hu, S.; Yang, X. Long-lived and thermoresponsive emulsion foams stabilized by self-assembled saponin nanofibrils and fibrillar network. Langmuir 2018, 34, 3971-3980.

23. Gao, Y.; Hao, J.; Wu, J.; Zhang, X.; Hu, J.; Ju, Y. Supramolecular helical nanofibers assembled from a pyridinium-functionalized methyl glycyrrhetate amphiphile. Nanoscale 2015, 7, 1356813575 .

24. Gao, Y.; Hao, J.; Yan, Q.; Du, F.; Ju, Y.; Hu, J. Natural triterpenoid-tailored phosphate: in situ reduction of heavy metals spontaneously to generate electrochemical hybrid gels. ACS Appl. Mater. Interfaces 2018, 10, 17352-17358.

25. Hao, J.; Gao, Y.; Li, Y.; Yan, Q.; Hu, J.; Ju, Y. Thermosensitive triterpenoid-appended polymers with broad temperature tunability regulated by host-guest chemistry. Chem. Asian. J. 2017, 12, 2231-2236.

26. Yang, Q.; Wang, P.; Zhao, C.; Wang, W.; Yang, J.; Liu, Q. Light-switchable self-Healing hydrogel based on host-guest macro-crosslinking. Macromol. Rapid. Commun. 2017, 38, 1600741.

27. Renard, E.; Deratani, A.; Volet, G.; Sebille, B. Preparation and characterization of water soluble high molecular weight $\beta$ cyclodextrin-epichlorohydrin polymers. Eur. Polym. J. 1997, 33, 49-57.

28. Li, G.; Wu, J.; Wang, B.; Yan, S.; Zhang, K.; Ding, J.; Yin, J. Self-healing supramolecular self-assembled hydrogels-based on poly (L-glutamic acid). Biomacromolecules 2015, 16, 3508-3518.

29. Haque, M. A.; Kurokawa, T.; Kamita, G.; Gong, J. Lamellar bilayers as reversible sacrificial bonds to toughen hydrogel: hysteresis, self-recovery, fatigue resistance, and crack blunting. Macromolecules 2011, 44, 8916-8924.

3o. Nakahata, M.; Mori, S.; Takashima, Y.; Yamaguchi, H.; Harada, A. Self-healing materials formed by cross-linked polyrotaxanes with reversible bonds. Chem 2016, 1, 766-775. 


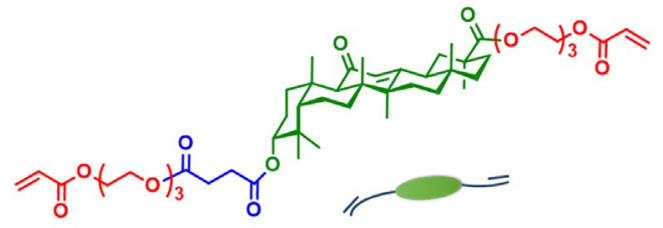

Glycyrrhetinic acid-derived alkene, GADA

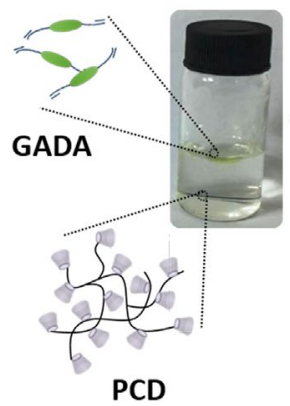

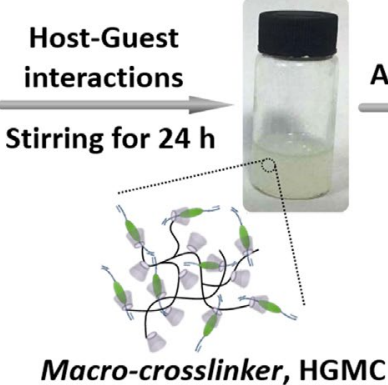

Host-Guest teraction

Macro-crosslinker, HGMC

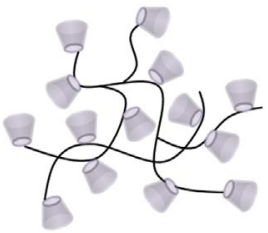

Poly( $\beta$-cyclodextrin), PCD

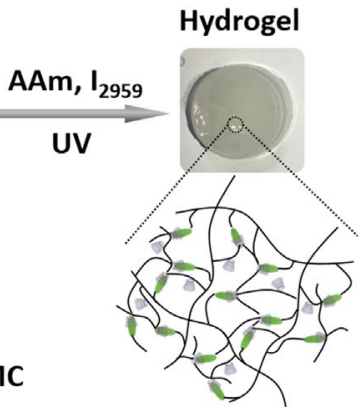




\section{Supporting Information}

\section{Tough Polymeric Hydrogels Formed by Natural Glycyrrhetinic Acid-Tailored Host-Guest Macro-Crosslinking Toward Biocompatible Materials}

Ge Xu, ${ }^{\dagger}$ Jiawei Li, ${ }^{\dagger}$ Jianqiao $\mathrm{Wu},{ }^{\dagger}$ Hao Zhang, ${ }^{\dagger}$ Jun $\mathrm{Hu}^{*}, \dagger$ and Min-Hui $\mathrm{Li}^{*,+, \ddagger}$

${ }^{\dagger}$ Beijing Advanced Innovation Center for Soft Matter Science and Engineering, Beijing University of Chemical Technology, Beijing 100029, China

${ }^{\ddagger}$ Chimie ParisTech, PSL University Paris, CNRS, Institut de Recherche de Chimie, Paris 75005, France

Email: jhu@mail.buct.edu.cn; min-hui.li@chimieparistech.psl.eu 


\section{Table of Content}

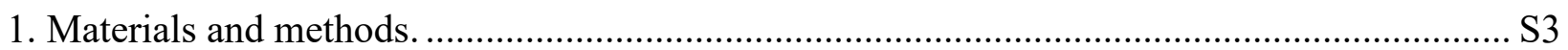

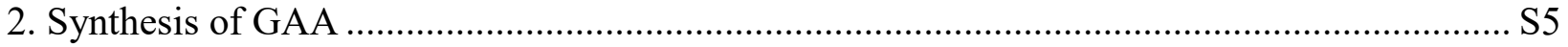

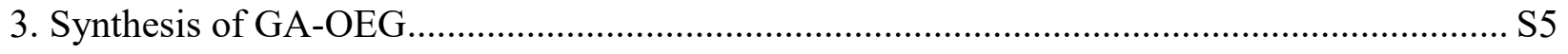

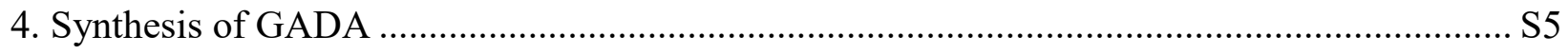

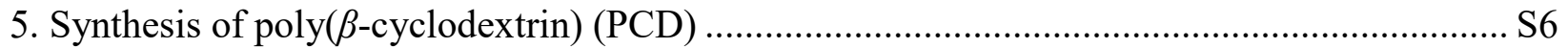

6. Fabrication of host-guest macro-crosslinker (HGMC) ...................................................... S6

7. Preparation of supramolecular polymeric hydrogels ...................................................... S6

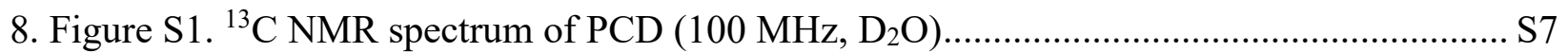

9. Figure S2. X-ray diffraction patterns of PCD, GADA and HGMC ....................................... 7

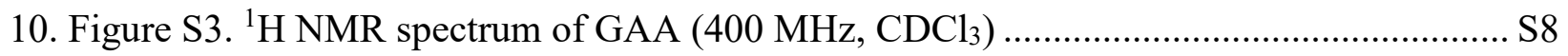

11. Figure S4. ${ }^{13} \mathrm{C}$ NMR spectrum of GAA $\left(100 \mathrm{MHz}, \mathrm{CDCl}_{3}\right)$......................................... S8

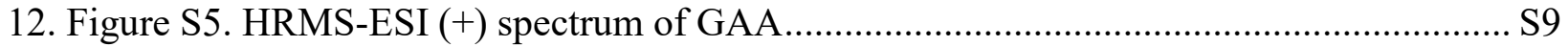

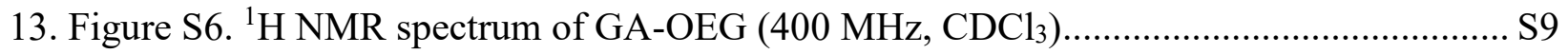

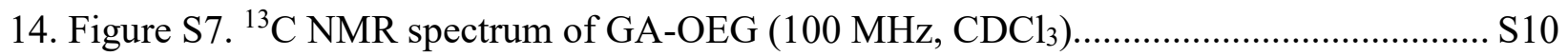

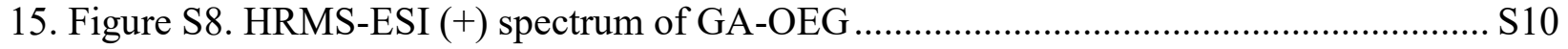

16. Figure S9. ${ }^{1} \mathrm{H}$ NMR spectrum of GADA $\left(400 \mathrm{MHz}, \mathrm{CDCl}_{3}\right)$....................................... S11

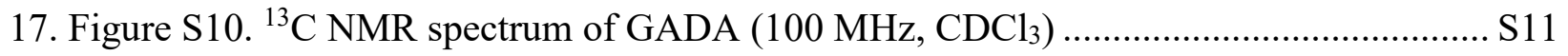

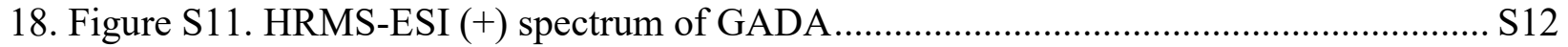

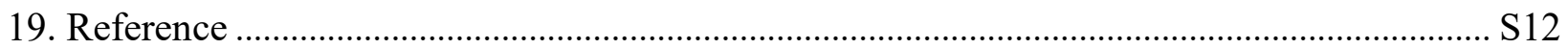


Materials and methods. Glycyrrhetinic acid, $\beta$-cyclodextrin, $\mathrm{I}_{2959}$, succinic anhydride, 2-[2-(2chloroethoxy)ethoxy]ethanol, epichlorohydrin, trimethylamine, acryloyl chloride, acrylamide, potassium carbonate, potassium iodide, potassium hydroxide and other reagents were local commercial products. Acrylamide was recrystallized from chloroform. Dialysis bag was purchased from Viskase. All organic solvents were dried and distilled before use.

NMR spectra were recorded on a Bruker AV400 spectrometer operating at $400 \mathrm{MHz}$. HRMSESI were performed on Ultra High Definition(UHD) Accurate-Mass Q-TOF LC-MS.

Molecular weight and polydispersity index (PDI) of polymers were determined by size exclusion chromatography (SEC) with an Agilent Technologies 1260 infinity LC equipped with quaternary gradient pump and a refractive-index detector (G1362A). DMF was used as eluent at a flow rate of $1.0 \mathrm{~mL} / \mathrm{min}$ at $23^{\circ} \mathrm{C}$, and polystyrene standards were employed for molecular weights calibration.

The swelling properties of hydrogels was estimated by the swelling ratio $(Q)$ of each sample during the interval measured at room temperature by weighting swollen hydrogels in water $\left(m_{\mathrm{w}}\right)$, followed by recording their dried mass $\left(m_{\mathrm{d}}\right)$ using the following equation:

$$
Q=\left(m_{\mathrm{w}}-m_{\mathrm{d}}\right) / m_{\mathrm{d}}
$$

The molar ratio between $\beta$-CD and GADA in host-guest macro-crosslinker HGMC can be calculated as Formula S1:

$$
=\frac{M_{n}(\mathrm{PCD})}{M_{w}(\beta-\mathrm{CD}+10 \text { epichlorohydrin-10 } \mathrm{HCl})} / \frac{M_{n}(\mathrm{HGMC})-M_{n}(\mathrm{PCD})}{M_{w}(\mathrm{GADA})}
$$

Where $M_{\mathrm{n}}(\mathrm{PCD})$ and $M_{\mathrm{n}}(\mathrm{HGMC})$ were obtained from SEC results, $M_{\mathrm{w}}(\mathrm{GADA})$ was afforded by ESI-MS $(+)$, and $M_{\mathrm{w}}(\beta-\mathrm{CD}+10$ epichlorohydrin $-10 \mathrm{HCl})$ was calculated according to the feed ratio of $\beta$-CD and epichlorohydrin in preparation of PCD.

XRD was conducted with an Ultima IV Goniometer from Rigaku by using CuKa radiation, and scanning was performed from 5 to $90^{\circ}$.

SEM images were obtained using a field emission scanning electron microscope (JSM-7610F with $10 \mathrm{kV}$ acceleration voltage). Square gels $(3 \mathrm{~mm} \times 2 \mathrm{~mm})$ at the swelling equilibrium were lyophilized under vacuum at $-60^{\circ} \mathrm{C}$. Before subjecting to SEM analysis, gold was coated on dry gels. 
Rheological characterization of hydrogels was done with an AR 2000 rheometer (TA Instruments) equipped with a $2^{\circ}$ steel cone geometry of $20 \mathrm{~mm}$ diameter and solvent trap. They were monitored by time sweep, frequency sweep, and strain sweep experiments.

Compression tests were performed on an electronic universal testing machine (SANS, CMT4000, CN), and the hydrogels had the cylindrical shape (height $10.24 \mathrm{~mm}$, diameter 18.71 $\mathrm{mm}$ ) for compression and cyclic compression tests. While tensile tests were performed on a universal test machine (UTM, Instron 3345, USA). The specimens were of $20 \mathrm{~mm}$ width and 2 $\mathrm{mm}$ thickness with a testing gauge length of $5 \mathrm{~cm}$. 
Synthesis of GAA. GAA was synthesized according to the literature. ${ }^{[1]}{ }^{1} \mathrm{H} \mathrm{NMR}\left(400 \mathrm{MHz}, \mathrm{CDCl}_{3}\right.$, ppm): $\delta=5.69(\mathrm{~s}, 1 \mathrm{H}, 12-\mathrm{H}), 4.54\left(\mathrm{dd}, 1 \mathrm{H}, J_{1}=12 \mathrm{~Hz}, J_{2}=4 \mathrm{~Hz}, 3-\mathrm{H}\right), 2.80(\mathrm{~m}, 1 \mathrm{H}, 18-\mathrm{H}), 2.64-$ $2.69\left(\mathrm{~m}, 2 \times 2 \mathrm{H},-\mathrm{O}_{2} \mathrm{CCH}_{2} \mathrm{CH}_{2} \mathrm{CO}_{2}-\right), 1.36,1.21,1.16,1.12,0.88,0.83\left(\mathrm{~s}, 7 \times 3 \mathrm{H}, 7 \times \mathrm{CH}_{3}\right) ;{ }^{13} \mathrm{C}$ NMR (100 MHz, $\left.\mathrm{CDCl}_{3}, \mathrm{ppm}\right): \delta=200.3,182.4,178.1,172.0,169.4,128.6,81.4,61.8,55.2,48.3$, 45.6, 44.0, 43.3, 40.9, 38.9, 38.3, 37.8, 37.1, 32.8, 32.0, 31.0, 29.5, 29.2, 28.7, 28.6, 28.1, 26.6, 26.5, 23.6, 23.5, 18.8, 17.5, 16.9, 16.5; HRMS-ESI $(+): \mathrm{m} / \mathrm{z}[\mathrm{M}+\mathrm{H}]^{+}$calcd. for $\mathrm{C}_{34} \mathrm{H}_{51} \mathrm{O}_{7}$ : 571.3635, found 571.3631; m/z [2M + H] $]^{+}$calcd. for $\mathrm{C}_{68} \mathrm{H}_{101} \mathrm{O}_{14}: 1141.7191$, found 1141.7222.

Synthesis of GA-OEG: GAA (4.50 g, $7.95 \mathrm{mmol})$, 2-[2-(2-chloroethoxy)ethoxy]ethanol (2.60 $\mathrm{mL}, 17.49 \mathrm{mmol})$, potassium carbonate $(3.31 \mathrm{~g}, 23.95 \mathrm{mmol})$ and potassium iodide $(5.30 \mathrm{~g}, 31.90$ mmol) were added in dry DMF (15 mL), and then the mixture was stirred at $60{ }^{\circ} \mathrm{C}$ for $14 \mathrm{~h}$. After filtering precipitates, the filtrate was concentrated under reduced pressure and the crude was further purified by silica gel chromatography (dichloromethane/methanol $=30: 1, \mathrm{v} / \mathrm{v}$ ) to afford GA-OEG as a colorless oil (6.50 g, yield $95 \%)$. ${ }^{1} \mathrm{H}$ NMR (400 MHz, $\left.\mathrm{CDCl}_{3}, \mathrm{ppm}\right): \delta=5.67$ (s, $1 \mathrm{H}, 12-\mathrm{H}), 4.54\left(\mathrm{dd}, 1 \mathrm{H}, J_{1}=12 \mathrm{~Hz}, J_{2}=4 \mathrm{~Hz}, 3-\mathrm{H}\right), 4.17-4.37\left(\mathrm{~m}, 2 \times 2 \mathrm{H},-\mathrm{CO}_{2} \mathrm{CH}_{2} \mathrm{CH}_{2}-\right), 3.36-$ $3.73\left(\mathrm{~m}, 10 \times 2 \mathrm{H},-\mathrm{OCH}_{2} \mathrm{CH}_{2} \mathrm{O}-\right), 2.80(\mathrm{~m}, 1 \mathrm{H}, 18-\mathrm{H}), 2.64-2.67\left(\mathrm{~m}, 2 \times 2 \mathrm{H}_{,}-\mathrm{O}_{2} \mathrm{CCH}_{2} \mathrm{CH}_{2} \mathrm{CO}_{2-}\right)$, 1.36, 1.16, 1.15, 1.12, 0.87, $0.80\left(\mathrm{~s}, 7 \times 3 \mathrm{H}, 7 \times \mathrm{CH}_{3}\right) ;{ }^{13} \mathrm{C} \mathrm{NMR}\left(100 \mathrm{MHz}, \mathrm{CDCl}_{3}, \mathrm{ppm}\right): \delta=$ 199.3, 175.5, 171.5, 171.1, 168.7, 127.5, 80.2, 71.6, 70.0, 69.7, 69.6 69.5, 68.4, 68.2, 62.8, 62.4, 61.0, 60.9, 54.2, 47.4, 44.6, 43.2, 42.3, 40.2, 37.9, 37.2, 36.8, 36.1, 31.8, 31.0, 30.3, 28.6, 28.3, 27.7, 27.4, 27.2 26.0, 25.6, 22.7, 22.5, 17.8, 16.5, 15.8, 15.5; HRMS-ESI (+): m/z [M+ Na $]^{+}$calcd. for $\mathrm{C}_{46} \mathrm{H}_{74} \mathrm{O}_{13} \mathrm{Na}$ : 857.5027, found 857.5031.

Synthesis of GADA. Acryloyl chloride $(1.58 \mathrm{~mL}, 19.46 \mathrm{mmol})$ was added dropwise to a dry dichloromethane solution of GA-OEG $(6.50 \mathrm{~g}, 7.78 \mathrm{mmol})$ and triethylamine $(4.30 \mathrm{~mL}, 31.90$ $\mathrm{mmol}$ ) at $0^{\circ} \mathrm{C}$, and then the mixture was stirred at room temperature for $6 \mathrm{~h}$. After that, the mixture was quenched with dilute hydrochloric acid (1 M) and extracted with ethyl acetate. The organic layer was washed with water, brine, and dried with anhydrous $\mathrm{Na}_{2} \mathrm{SO}_{4}$. After removing the solvent under reduced pressure, the crude was further purified by silica gel chromatography (hexane/ethyl acetate $=1: 3, \mathrm{v} / \mathrm{v})$ to give GADA as a light yellow oil $(5.18 \mathrm{~g}$, yield $70 \%)$. ${ }^{1} \mathrm{H} \mathrm{NMR}(400 \mathrm{MHz}$, $\left.\mathrm{CDCl}_{3}, \mathrm{ppm}\right): \delta=6.42\left(\mathrm{~d}, 2 \times 1 \mathrm{H}, J=16 \mathrm{~Hz}, \mathrm{CH}_{2}=\mathrm{CHCO}_{2}-\right), 6.16\left(\mathrm{dd}, 2 \times 1 \mathrm{H}, J_{1}=16 \mathrm{~Hz}, J_{2}=\right.$ $\left.12 \mathrm{~Hz}, \mathrm{CH}_{2}=\mathrm{C} \boldsymbol{H}-\mathrm{CO}_{2}-\right), 5.84\left(\mathrm{~d}, 2 \times 1 \mathrm{H}, J=12 \mathrm{~Hz}, \mathrm{CH}_{2}=\mathrm{CHCO}_{2-},\right), 5.66(\mathrm{~s}, 1 \mathrm{H}, 12-\mathrm{H}), 4.54(\mathrm{~m}$, $1 \mathrm{H}, 3-\mathrm{H}), 4.17-4.32\left(\mathrm{~m}, 4 \times 2 \mathrm{H},-\mathrm{CO}_{2} \mathrm{CH}_{2} \mathrm{CH}_{2}-\right), 3.66-3.75\left(\mathrm{~m}, 8 \times 2 \mathrm{H},-\mathrm{OCH}_{2} \mathrm{CH}_{2} \mathrm{O}-\right), 2.80(\mathrm{~m}$, 
$1 \mathrm{H}, 18-\mathrm{H}), 2.64\left(\mathrm{~m}, 2 \times 2 \mathrm{H},-\mathrm{O}_{2} \mathrm{CCH}_{2} \mathrm{CH}_{2} \mathrm{CO}_{2}-\right), 1.36,1.15,1.11,0.87,0.80\left(\mathrm{~s}, 7 \times 3 \mathrm{H}, 7 \times \mathrm{CH}_{3}\right)$; ${ }^{13} \mathrm{C}$ NMR (100 MHz, $\left.\mathrm{CDCl}_{3}, \mathrm{ppm}\right): \delta=200.1,176.5,172.5,172.0,169.5,166.3,131.2,131.1$, $128.6,128.4,128.3,81.2,77.4,70.8,70.7,70.6,70.5,69.4,69.3,69.2,63.9,63.8,63.7,63.4,61.8$, 55.2, 48.4, 45.5, 44.2, 43.3, 41.2, 38.9, 38.2, 37.8, 37.1, 32.8, 31.9, 31.3, 29.6, 29.3, 28.7, 28.4, 28.2, 26.6, 26.5, 23.7, 23.5, 18.8, 17.5, 16.8, 16.5; HRMS-MS (+): $\mathrm{m} / \mathrm{z}[\mathrm{M}+\mathrm{Na}]^{+}$calcd. for $\mathrm{C}_{52} \mathrm{H}_{78} \mathrm{O}_{15} \mathrm{Na}: 965.5238$, found 965.5249 .

Synthesis of poly(ק-cyclodextrin) (PCD). $\beta$-CD $(5.00 \mathrm{~g}, 4.40 \mathrm{mmol})$ was added in $\mathrm{NaOH}$ solution $\left(33 \mathrm{wt} \%, 8 \mathrm{~mL}\right.$ ) and then the mixture was stirred at $30^{\circ} \mathrm{C}$ for $3 \mathrm{~h}$ until a clear solution formed. After that, epichlorohydrin $(3.42 \mathrm{~mL}, 43.65 \mathrm{mmol})$ was added rapidly and the polymerization was kept at $30{ }^{\circ} \mathrm{C}$ in a rapid stirring $(800 \mathrm{rpm})$ for $20 \mathrm{~min}$. After quenching by acetone, the excess acetone was removed under reduced pressure and the $\mathrm{pH}$ was adjusted to 10 with $\mathrm{HCl}(4 \mathrm{M})$. The solution was dialyzed (molecular weight 3000) for 4 days and lyophilized to afford PCD as a white powder (2.94 g, yield 33\%). ${ }^{13} \mathrm{C}$ NMR (100 MHz, $\left.\mathrm{D}_{2} \mathrm{O}, \mathrm{ppm}\right): \delta=101.9,81.1,73.1,72.1,71.8$, $70.5,69.1,67.9,62.5,60.3 ; M_{\mathrm{n}}=7257 \mathrm{Da}, \mathrm{PDI}=1.16$.

Fabrication of host-guest macro-crosslinker (HGMC). Initially, GADA (113 mg, $0.12 \mathrm{mmol}$ ) was mixed with the PCD dispersion (500 mg, $2.00 \mathrm{~mL}$ ) at room temperature, and then the mixture was stirred at room temperature for $24 \mathrm{~h}$. After that, the mixture was kept in $25{ }^{\circ} \mathrm{C}$ before the copolymerization.

Preparation of supramolecular polymeric hydrogels. In general, acrylamide (AAm, $852 \mathrm{mg}$, $12 \mathrm{mmol}$ ), $\mathrm{I}_{2959}(5 \mathrm{mg}, 0.022 \mathrm{mmol}$ ) and $2.00 \mathrm{~mL}$ macro-crosslinker HGMC dispersion were mixed at $25^{\circ} \mathrm{C}$, and then the mixture was transferred into a cylindrical mould (diameter $=20 \mathrm{~mm}$, height $=40 \mathrm{~mm}$ ) and sealed. After UV copolymerizing at $365 \mathrm{~nm}$ for $8 \mathrm{~h}$, a polymeric hydrogel (Gel-1) with the cylindrical shape was obtained. Gel-2 and Gel-3 with different molar ratios of HGMC and AAm were prepared in a similar way. The feed ratios were summarized in Table 1. 

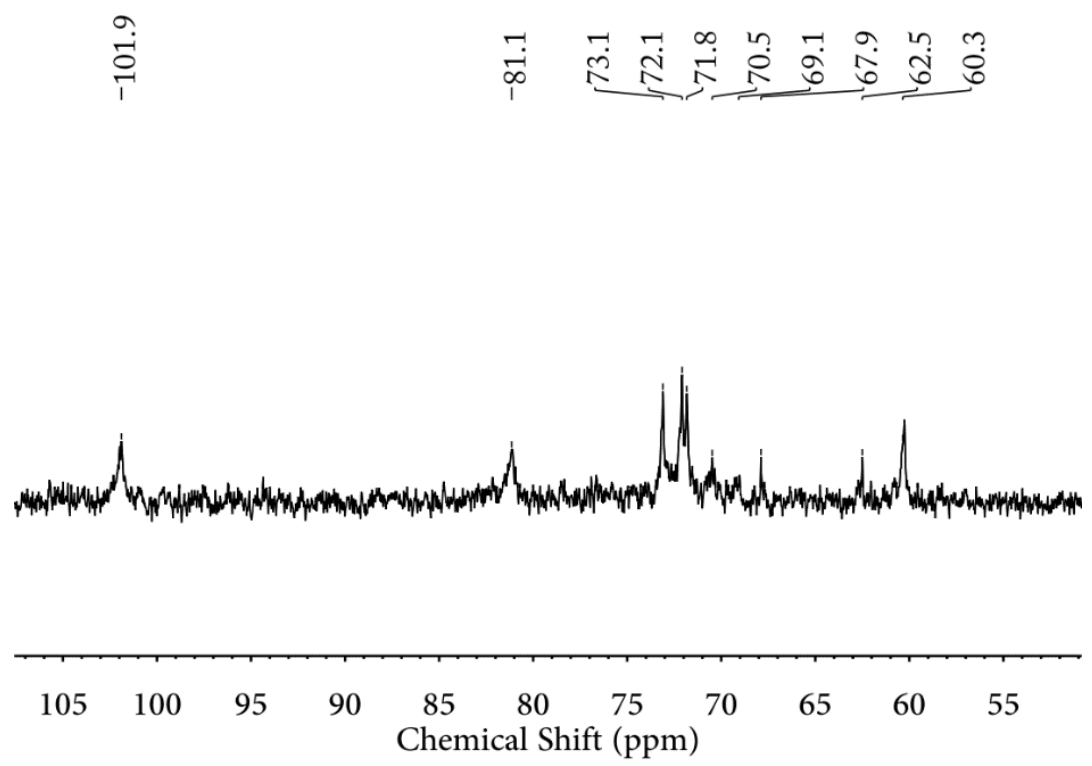

Figure S1. ${ }^{13} \mathrm{C}$ NMR spectrum of PCD $\left(100 \mathrm{MHz}, \mathrm{D}_{2} \mathrm{O}\right)$.

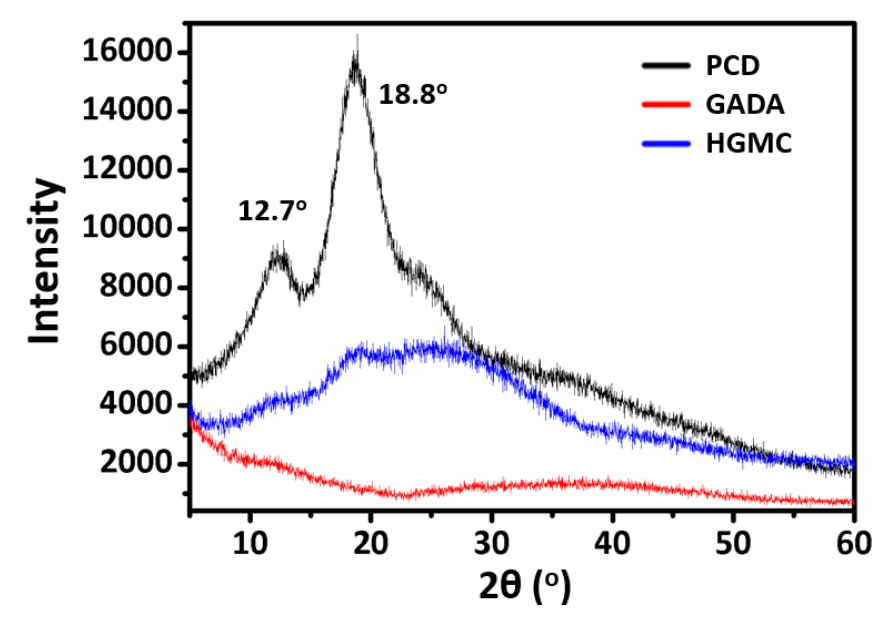

Figure S2. X-ray diffraction patterns of PCD, GADA and HGMC. 


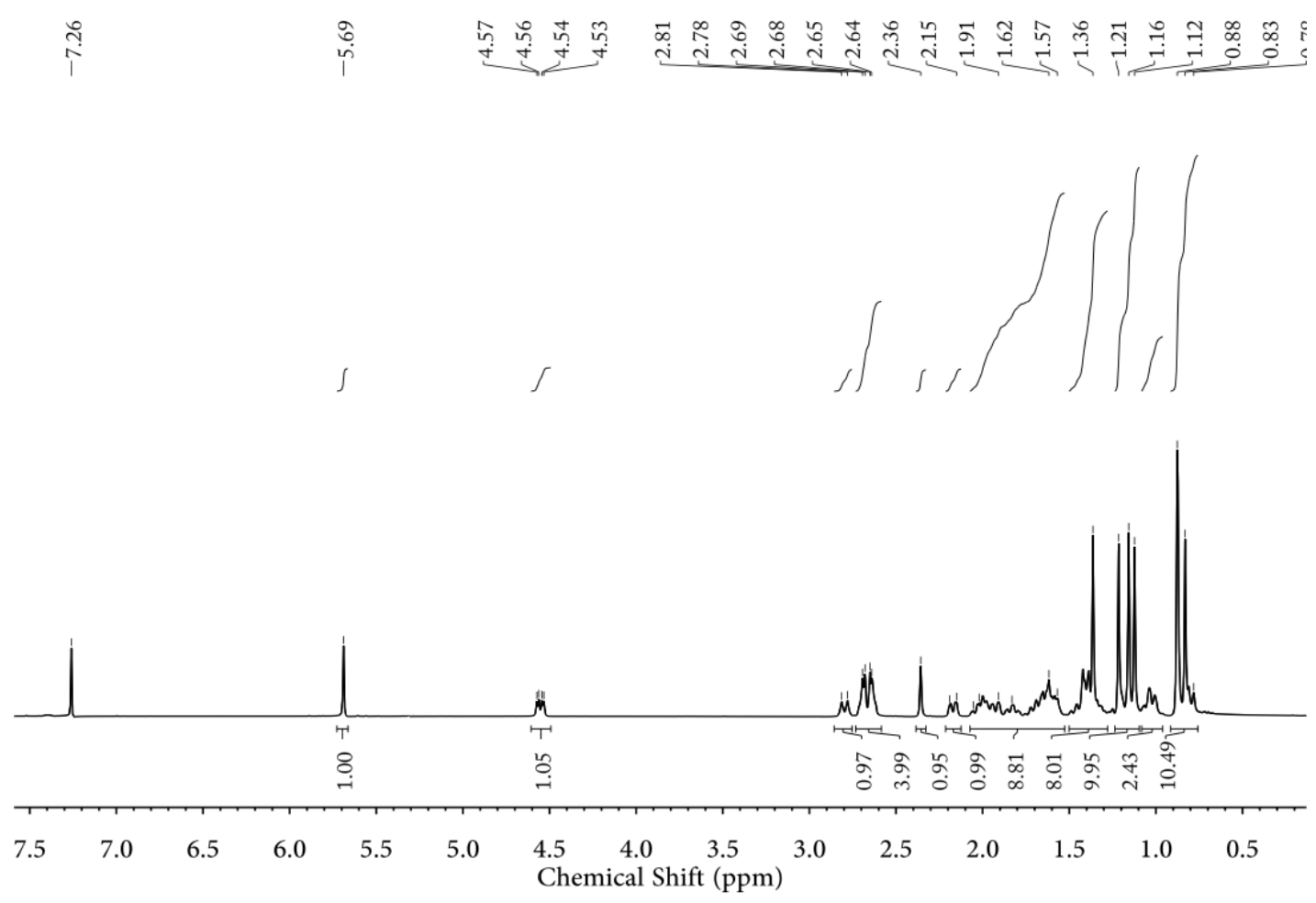

Figure S3. ${ }^{1} \mathrm{H}$ NMR spectrum of GAA $\left(400 \mathrm{MHz}, \mathrm{CDCl}_{3}\right)$

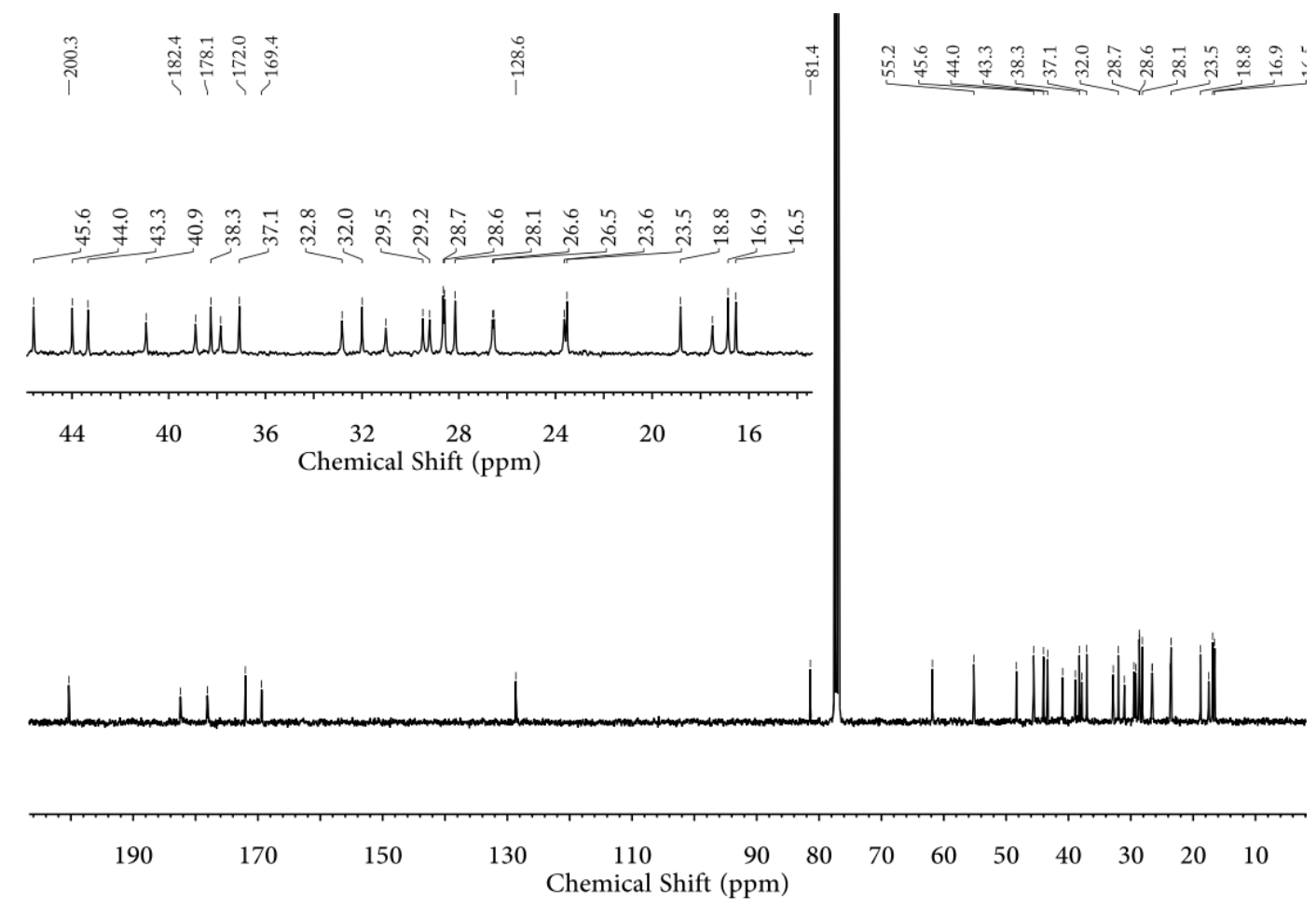

Figure S4. ${ }^{13} \mathrm{C}$ NMR spectrum of GAA $\left(100 \mathrm{MHz}, \mathrm{CDCl}_{3}\right)$ 


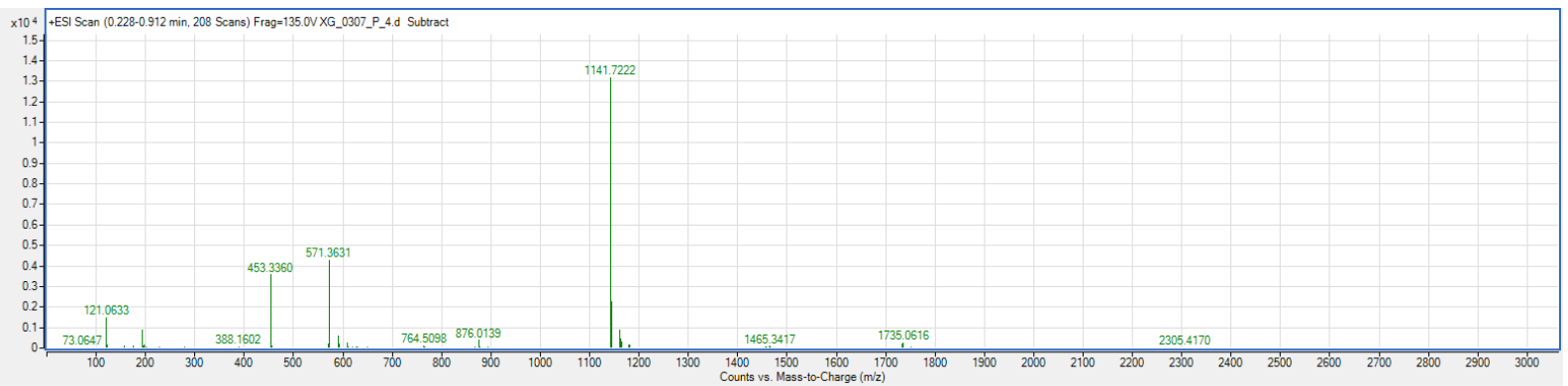

Figure S5. HRMS-ESI $(+)$ spectrum of GAA

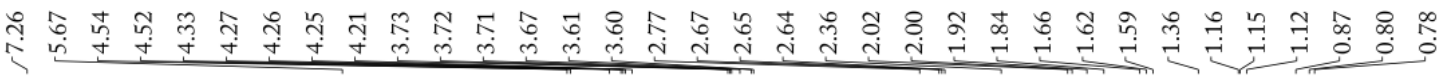

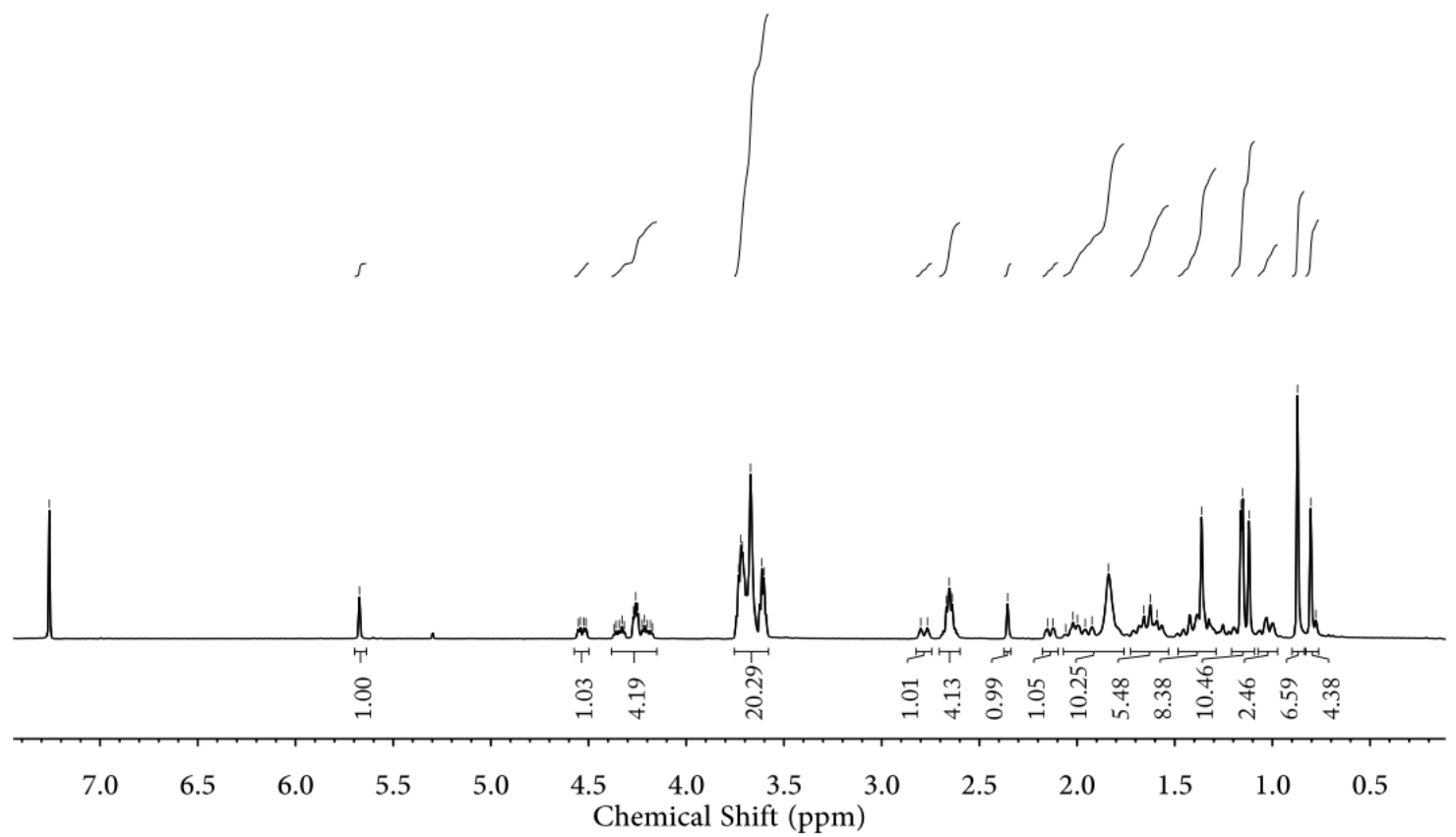

Figure S6. ${ }^{1} \mathrm{H}$ NMR spectrum of GA-OEG (400 $\left.\mathrm{MHz}, \mathrm{CDCl}_{3}\right)$ 

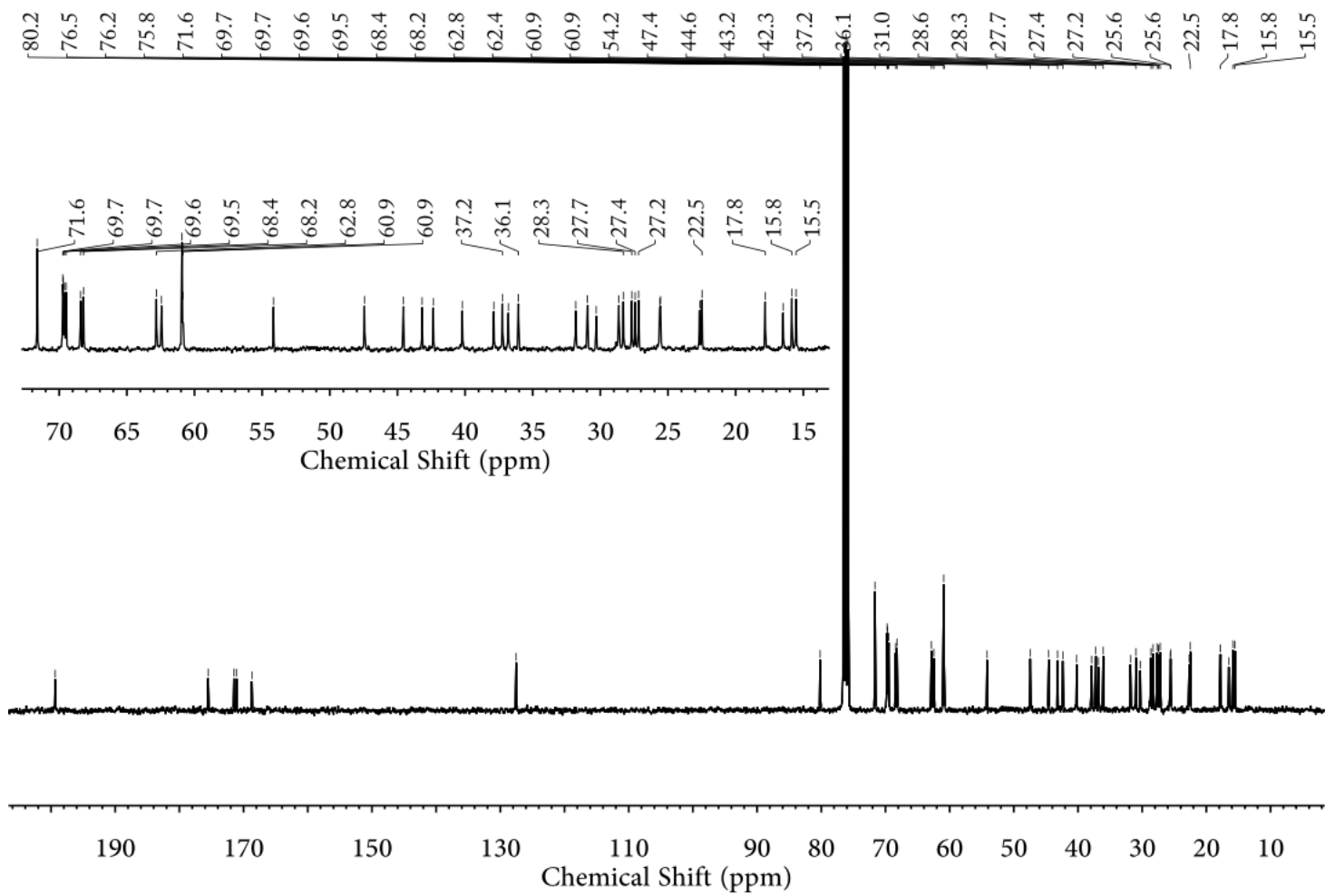

Figure S7. ${ }^{13} \mathrm{C}$ NMR spectrum of GA-OEG (100 MHz, $\left.\mathrm{CDCl}_{3}\right)$

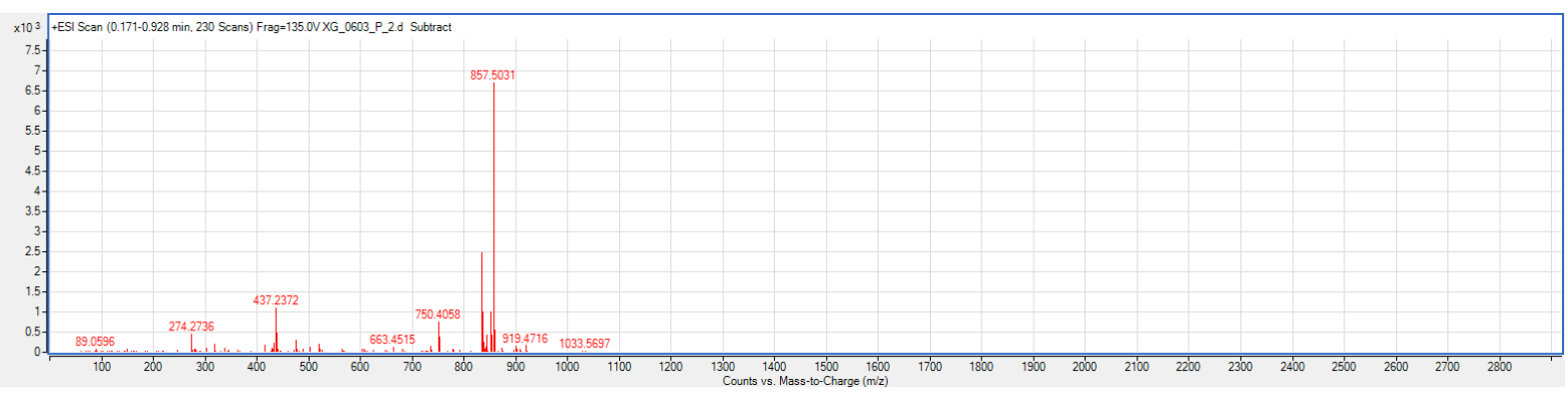

Figure S8. HRMS-ESI $(+)$ spectrum of GA-OEG 


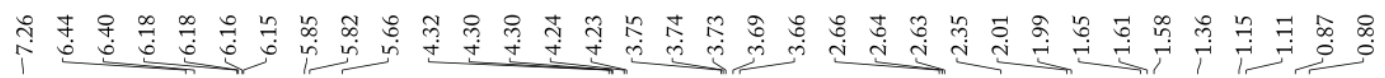

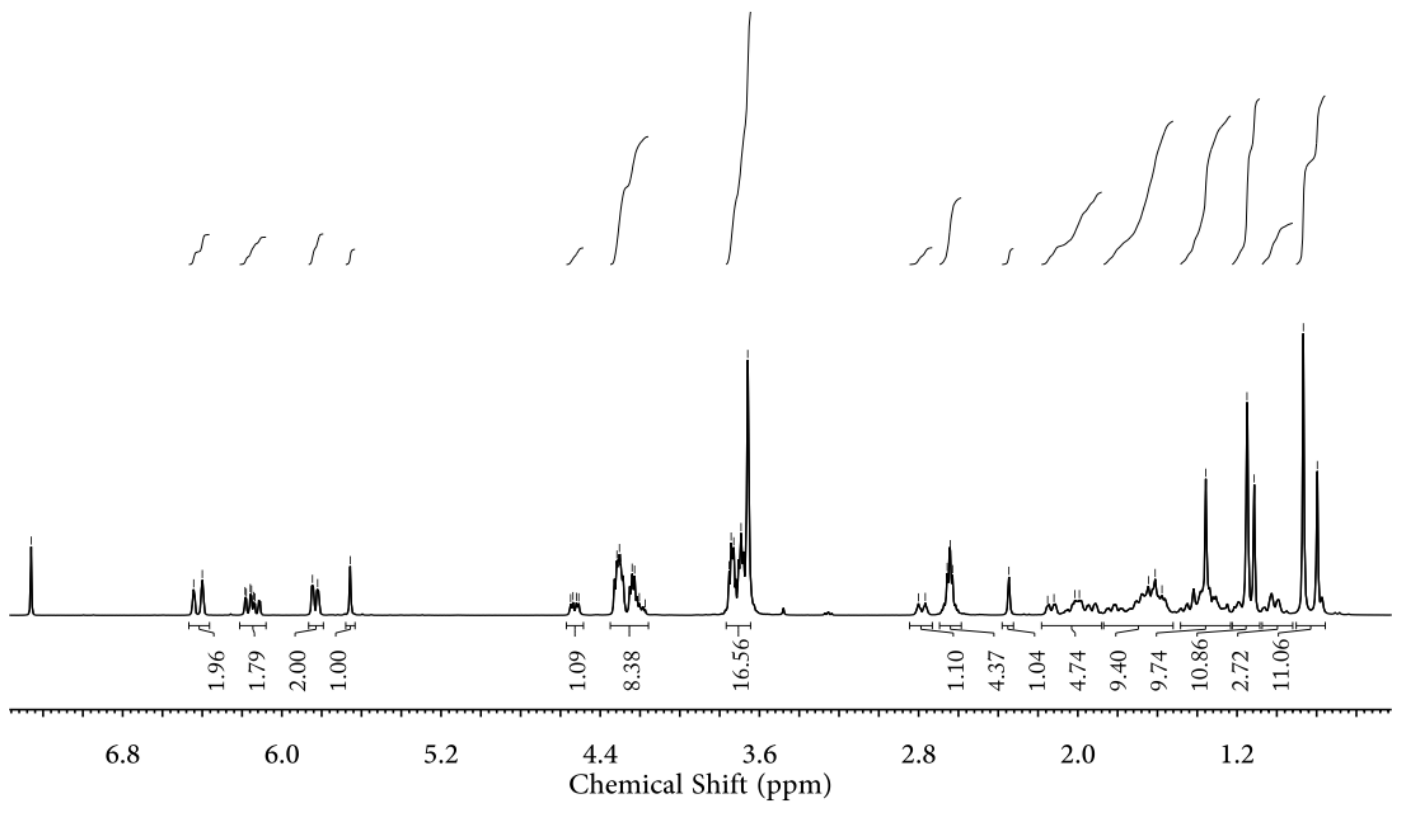

Figure S9. ${ }^{1} \mathrm{H}$ NMR spectrum of GADA $\left(400 \mathrm{MHz}, \mathrm{CDCl}_{3}\right)$

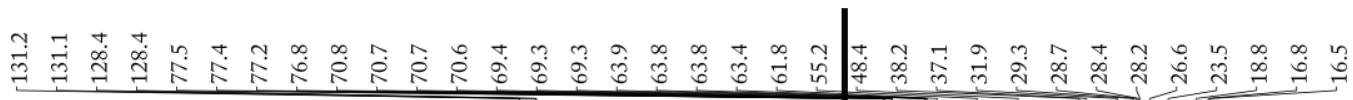

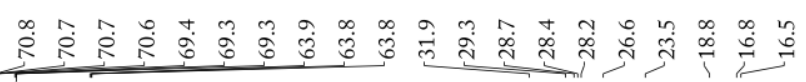
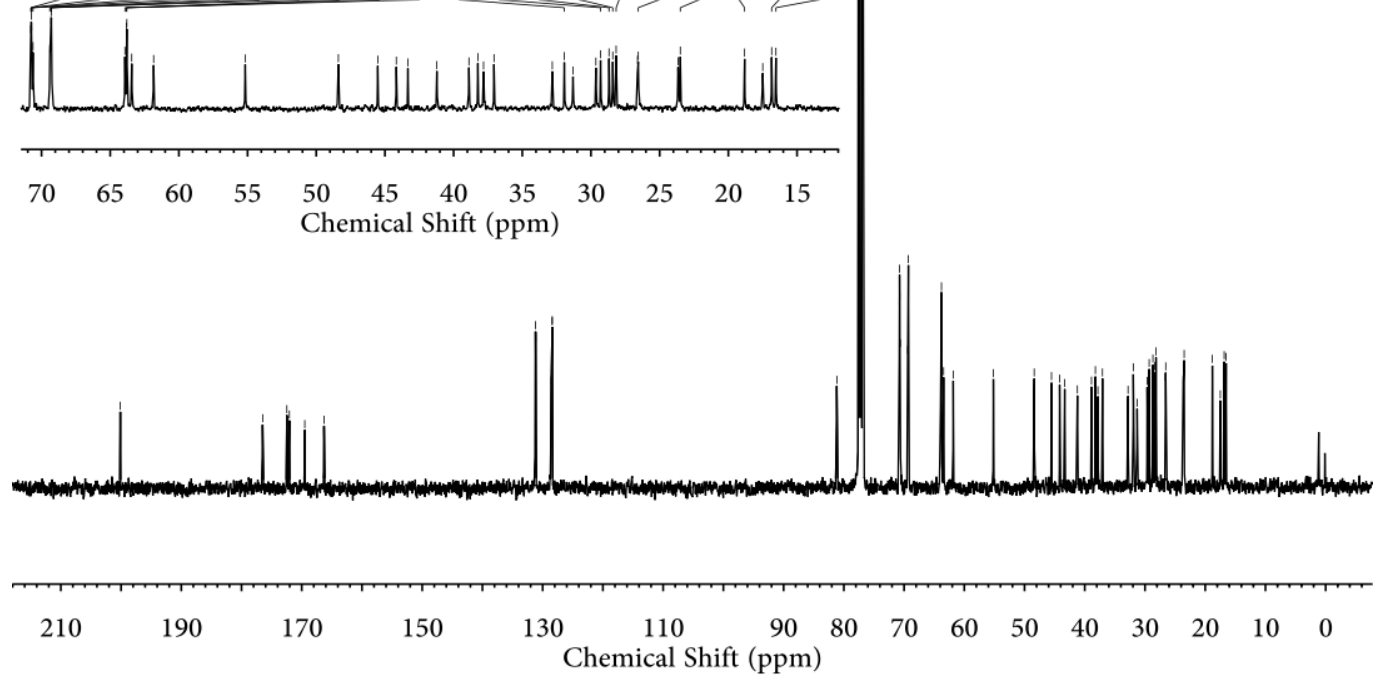

Figure S10. ${ }^{13} \mathrm{C}$ NMR spectrum of GADA (100 MHz, $\left.\mathrm{CDCl}_{3}\right)$ 


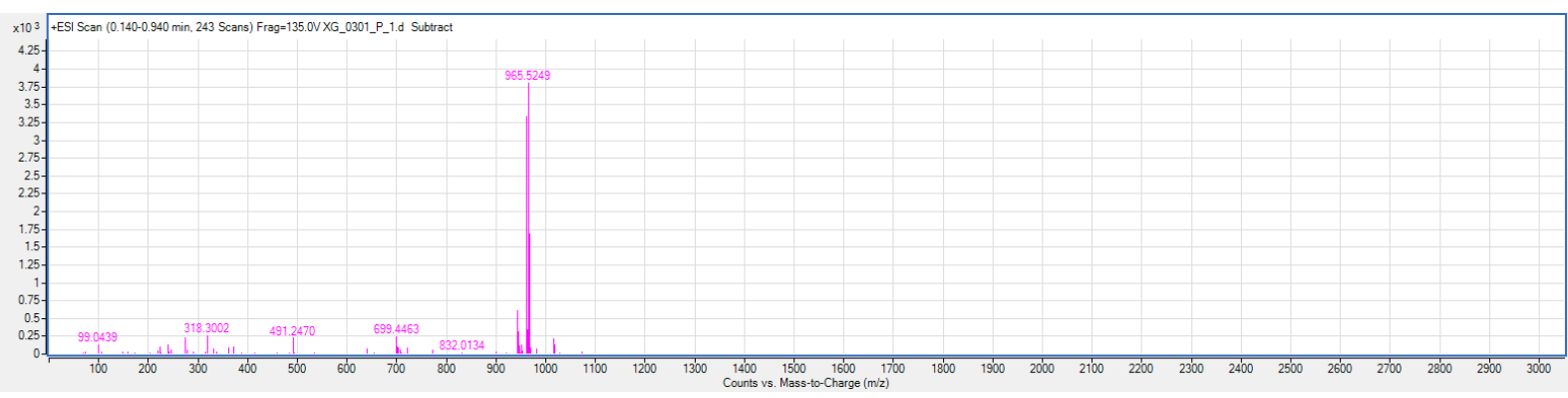

Figure S11. HRMS-ESI (+) spectrum of GADA

\section{Reference}

[1] Feng, R.; Deng, P.; Song, Z.; Chu, W.; Zhu, W.; Teng, F.; Zhou, F. Glycyrrhetinic acidmodified PEG-PCL copolymeric micelles for the delivery of curcumin. React. Funct. Polym. 2017, 111, 30-37. 